University of Louisville

ThinkIR: The University of Louisville's Institutional Repository

Faculty Scholarship

$12-2011$

\title{
A randomized trial to evaluate the course of effects of a program to prevent adolescent depressive symptoms over 12 months.
}

\author{
Patrick Pössel \\ University of Louisville \\ Jill L. Adelson \\ University of Louisville \\ Martin Hautzinger \\ Eberhard-Karls-Universitat Tubingen
}

Follow this and additional works at: https://ir.library.louisville.edu/faculty

Part of the Counseling Psychology Commons

Original Publication Information

Pössel, Patrick, Jill L. Adelson and Martin Hautzinger. "A Randomized Trial to Evaluate the Course of Effects of a Program to Prevent Adolescent Depressive Symptoms over 12 Months." 2011. Behaviour Research and Therapy 49(12): 838-851.

This Article is brought to you for free and open access by ThinkIR: The University of Louisville's Institutional Repository. It has been accepted for inclusion in Faculty Scholarship by an authorized administrator of ThinkIR: The University of Louisville's Institutional Repository. For more information, please contact thinkir@louisville.edu. 
A Randomized Trial to Evaluate the Course of Effects of a Program to Prevent Adolescent Depressive Symptoms over 12 Months

Patrick Pössel ${ }^{1}$, Jill L. Adelson, and Department of Educational and Counseling Psychology, University of Louisville, Louisville, KY, USA

\section{Martin Hautzinger}

Department of Clinical and Developmental Psychology, Eberhard-Karls-University, Tübingen, Germany

Corresponding author:

Patrick Pössel, Dr. rer. soc.

Dep. of Educational and Counseling Psychology

University of Louisville

2301 S. Third Street

Louisville, KY 40292

USA

$+1-(502) 852-0623$ (office)

+1-(502)852-0629 (fax)

e-mail: patrick.possel@louisville.edu

\footnotetext{
1 Patrick Pössel is now faculty in the Department of Educational and Counseling Psychology at the University
} of Louisville. 


\begin{abstract}
Although few prevention studies have been designed to investigate the course of prevention effects over time, it seems that the effects on depressive symptoms increase from postintervention to 6-month follow-up but then decrease with longer lags to follow-up. Furthermore, previous prevention studies have found differential intervention effects for boys and girls without testing possible explanations for this effect. The present randomized control group study with 301 8th-grade students examined the effects of a depression prevention program from baseline until 12-month follow-up. As expected, while positive intervention effects were found on girls' depressive symptoms, no such effects were found on boys' depressive symptoms. Further, the positive intervention effects on girls' depressive symptoms increased to the 6-month follow-up and remained stable through the 12-month follow-up, while depression symptoms in control-group girls increased from 6-month to 12month follow-up. Further exploratory analyses revealed that neither baseline conduct problems nor cognitive or social knowledge of the prevention program at 12-month follow-up alone explained the sex effect. However, some limited evidence was found indicating that total knowledge (cognitive and social) might partially explain the effect but there was significant variability remaining to be explained.
\end{abstract}

Keywords: long-term effects; sex effects; school-based prevention; depression; adolescents 


\section{Prevention Programs for Adolescent Depression}

According to a recent meta-analysis of epidemiological studies, point prevalence rates of adolescent major depression are 5.9\% for girls and $4.6 \%$ for boys between 13 and 18 years (Costello, Erkanli, \& Angold, 2006). In addition, 15\% to $20 \%$ of children and adolescents experience at least one depressive episode before adulthood (Costello, Foley, \& Angold, 2006). Further, studies show that most individuals experience first onset of depression in adolescence (Hankin et al., 1998), and the consequences of the early development of depressive disorders may persist for years after adolescence. Individuals with past depression are two to seven times more likely to experience a recurrence of depression (Rutter, Caspi, \& Moffitt, 2003; Weissman et al., 1999) and other psychopathologies in adulthood (Birmaher et al., 1996). Even so-called "subsyndromal depression" has been shown to be a serious risk factor for depressive episodes in youth or later in life (Georgiades, Lewinsohn, Monroe, \& Seeley, 2006). A considerable number of depressed adolescents remain untreated despite the relatively high incidence of adolescent depression and its associated, frequently severe, impairments. Furthermore, adolescent girls are two to three times more likely to develop depression than their male peers (Birmaher et al., 1996).

In response to the high incidence and negative long-term effects of depressive symptoms and major depression in adolescents as well as the inadequacy of current mental health services for adolescents, five cognitive-behavioral, school-based universal prevention programs of depressive symptoms for adolescents have emerged from different labs. Only one of these prevention programs (Clarke, Hawkins, Murphy, \& Sheeber, 1993) showed no effect at all on the depressive symptomatology of participating adolescents. All of the other programs have shown some positive effects by preventing the development of depressive symptoms or reducing the increase of an already existing depressive symptomatology (Brunwasser, Gillham, \& Kim, 2009; Merry, McDowell, Wild, Bir, \& Cunliffe, 2004; Pössel, 
Horn, Groen, \& Hautzinger, 2004; Shochet et al., 2001; Spence, Sheffield, \& Donovan, 2003, 2005).

The LARS\&LISA program (described in The School-Based Prevention Program, below; Pössel, Horn, Seemann, et al., 2004), for example, was evaluated in four studies in Germany (Groen, Pössel, Al-Wiswasi \& Petermann, 2003; Pössel, Baldus, Horn, Groen, \& Hautzinger, 2005; Pössel, Horn, Groen et al., 2004; Wahl, Patak, Pössel \& Hautzinger, in press; reference omitted for blind review) and one in Colombia (Gómez, Jimenez \& Restrepo, 2004). All studies found positive effects on depressive or aggressive symptoms in participating adolescents. Differential analyses revealed that (a) non-depressed adolescents and adolescents with subsyndromal depression benefit from participating in LARS\&LISA (Pössel, Horn, Groen et al., 2004); (b) students with low self-efficacy benefited more than students with high self-efficacy (Pössel et al., 2005); (c) comorbid anxious symptoms and conduct problems have no negative effects on the effects of LARS\&LISA (reference omitted for blind review). Finally, LARS\&LISA demonstrated its positive effects on depressive symptoms not only compared to non-intervention control groups but also compared to a prevention program based on Pennebaker's (Pennebaker \& Beal, 1986) expressive writing paradigm (Pössel, Horn, \& Hautzinger, 2006).

Interestingly, it seems that the positive effects of the prevention programs on adolescent depressive symptoms follow a reversed U-shape over time. Compared to baselinepost-intervention comparisons, the magnitude of effect sizes of the prevention programs on depressive symptoms at 6-month follow-up seem to increase but then started to decrease with longer time lags between the end of the prevention program and follow-up time point (for a review, see Pössel, Schneider, \& Seemann, 2006). This hypothesis is partially supported by a recent meta-analysis (Stice et al., 2009) that found no statistically significant effects of universal prevention programs on adolescent depression at post-intervention $(r=.04, p=\mathrm{ns})$ but did find statistically significant effects at follow-up $(r=.06, p<.001)$. In addition, a 
meta-analysis of cognitive-behavior therapy of depressed adults demonstrated a nominal increase in magnitude of effect size from post-intervention $(d=0.03)$ to 1 -3-month followups $(d=0.07)$, and from there to 4-6-month follow-ups $(d=0.13)$, before the magnitude of effect size decreased during 7-12-month $(d=0.06)$ and 13-24-month follow-ups $(d=0.05)$, again (Cuijpers, van Straten, Andersson, \& van Oppen, 2008).

An increase of magnitude of effect size from post-intervention to 6-month follow-up seems contrary to our expectations but makes sense considering the population that universal prevention programs for adolescents serve. First, the majority of participants of universal prevention programs are not depressed at the time of the intervention but, due to the intervention, may be protected from depression at some point in the future. Participants in the control group, however, lack this protection. Second, depression rate and severity of depressive symptoms increases dramatically in puberty, particularly in girls (Angold, Erkanli, Silberg, Eaves, \& Costello, 2002). Thus, universal prevention programs of depression in adolescents will unfold their full effects over time, causing an increase in effect size until the effects start to fade out.

Nevertheless, that the effects of universal prevention programs on depressive symptoms follow a reversed U-shape within 1 year after completion of the program is only hypothetical as no study examined the course of prevention program effects on depressive symptoms between post-intervention and 12 months in detail. The present study was designed to test the hypothesis by providing the effects of a universal prevention program on depressive symptoms at post-intervention, 6-month follow-up, and 12-month follow-up.

\section{Sex Effects in Prevention Studies}

Epidemiological studies indicate that adolescent girls have higher depression rates than boys (e.g., Angold et al., 2002). As such, it can be concluded that girls are more at-risk of developing depression. Furthermore, it can be hypothesized that girls are more likely to benefit from participating in depression prevention programs (i.e., as measured by more 
prevented cases and symptoms of depression in participants) compared with boys.

Surprisingly, the prevention literature reveals a more contradictory picture of sex effects. So far, nine studies have focused on the effect of sex on universal and targeted prevention of depressive symptoms in adolescents. Although some of these studies reported no sex effects (Chaplin et al., 2006; Clarke et al., 1993 [second study reported]; Merry et al., 2004; Shochet et al., 2001), other studies differed as to whether boys (Clarke et al., 1993 [first study reported]; Shatté, 1996) or girls (Gillham, Hamilton, Freres, Patton, \& Gallop, 2006; Petersen et al., 1997; Pössel, Seemann, \& Hautzinger, 2008) benefitted more from participating in prevention programs. Especially remarkable is that Shatté (1996) and Gillham et al. (2006) found opposite sex effects in their independent studies examining the Penn Resiliency Program (PRP). Finally, five recent meta-analyses led to contradictory post-intervention results: Horowitz and Garber (2006) found no sex effect; Stice et al. (2009) indicated that studies including a greater percentage of girls yielded greater effects; Merry, McDowell, Hetrick, Bir, and Muller (2006) showed that prevention reduced depression scores for boys but not girls; Brunwasser et al. (2009) found significant effects of the PRP in 6- to 8-month follow-ups for both sexes but in 12-month follow-ups only for boys; and Garber and Downs (2011) found a significant effect of sex on the effects of prevention programs at postintervention but not at follow-up. However, even at post-intervention studies with low $(\leq$ $52 \%)$ and high (> 52\%) percentage of girls did not differ significantly in their effects.

The phenomenon of contradictory sex effects is not limited to studies examining the prevention of depression. Studies about anxiety disorders in adolescents, for example, showed the same mixed results. Although some studies revealed that girls responded less to prevention than boys (Cobham, Dadds, \& Spence, 1998), others found prevention effects only in girls and not in boys (Barrett, Farrell, Ollendick, \& Dadds, 2006). Based on the contradictory empirical data related to sex effects, we posit these effects are not necessarily based on sex itself but on other confounding or mediating variables. In a prevention study, 
sex effects should disappear after controlling for these confounding or mediating variables.

Based on the contradictory sex effects in the literature, this hypothesis can be only exploratory in nature.

\section{Possible Reasons for Sex Effects in Prevention Studies}

A comprehensive comparison of these contradictory results leads to the conclusion that sex effects seem to be independent of the type of prevention program (universal vs. targeted), topics of the program (educational, cognitive, social, cognitive and social), time of assessment (post-intervention to 24-month follow-up), and age of the students (e.g., from sixth to tenth grade). Universal programs, for example, found no sex effects (Chaplin et al., 2006; Clarke et al., 1993 [second study reported]; Merry et al., 2004; Shochet et al., 2001), better effects for boys (Clarke et al., 1993 [first study reported]; Shatté, 1996), and better effects for girls (Pössel et al., 2008). Furthermore, studies of both universal (Pössel et al., 2008) and targeted prevention programs (Gillham et al., 2006; Petersen et al., 1997) found sex effects demonstrating greater benefits for participating girls than boys. These results do not support the idea that sex effects are related to the type of program employed. Similarly results concerning development (e.g., cognitive development, maturational status) are contradictory. Chaplin et al. (2006), for example, found no sex effects in their study with sixth- to eighth-grade students, whereas Shatté (1996) and Pössel et al. (2008) found sex effects in seventh- and eighth-grade students, respectively. Contradictory results in prevention research have been reported for differences in the sex composition of groups as well. For example, Pössel et al. (2008) demonstrated that sex effects exist not only in mixedsex groups (e.g., Petersen et al., 1997) but also in single-sex groups. However, Chaplin et al. (2006) found no difference in the effect of prevention on depressive symptoms in girls who participated in mixed-sex versus girls-only groups. These contradictory results reduce the likelihood that separating adolescents by sex results in sex effects. Different learning styles (for a review, see Honigsfeld \& Dunn, 2003) are unlikely as a possible explanation for sex 
effects based on the opposite sex effects found in Shatté's (1996) and Gillham et al.'s (2006) studies examining the same prevention program. Finally, in their analysis, Gillham et al. (2006) controlled for attendance rates, baseline levels of depressive symptoms, and comorbid conduct problems, making it unlikely that these variables are possible explanations for sex effects.

As so many variables seem unlikely as possible explanations for sex effects, the question remains, what else might lead to the contradictory results described in the empirical literature? We now discuss knowledge of the prevention program's content (social vs. cognitive) and conduct problems as possible explanations of the sex effects found in prevention studies.

To date, only Shatté (1996) and Gillham et al. (2006) have tried to explain the sex effects they found. Shatté (1996) discussed three different factors as possible explanations for boys benefiting more than girls. First, he posited that boys may find cognitive programs (i.e., the logical dissection of emotions based on cognitive theories) more appealing and that girls may prefer social programs (i.e., experiential and expressive programs, stressing interpersonal situations like friendships, family, and trust). This argument is partially supported by a prevention study that showed that after participating in a prevention program, girls used their social networks more frequently and boys exhibited no change in the frequency with which they used their social networks (Pössel, Horn, \& Hautzinger, 2003). Second, in a mixed-sex group, boys may dominate group dynamics, pushing girls to the periphery (Shatté, 1996). Finally, Shatté (1996) argued that boys are generally more disruptive in a group than girls, which causes group leaders to focus more on boys and to push them into tasks more than they would with girls to regain control of the group. Contrary to Shatté (1996), Gillham et al. (2006) explained their result (i.e., that girls benefitted more than boys) by referring to the reported increase of stressful life events among teenage girls (Ge, Conger, \& Elder, 2001; 
Hankin \& Abramson, 2001). They concluded that girls may be more motivated to master trained skills and may have more opportunities to apply these skills in their everyday lives.

Another important factor related to sex effects might be the level of conduct problems at baseline in both sexes. Although Gillham et al. (2006) controlled for conduct problems, higher levels of conduct problems in one sex could be the reason for reported sex effects. Research has shown that therapeutic groups with adolescents demonstrating high levels of conduct problems lead to iatrogenic effects (Gifford-Smith, Dodge, Dishion, \& McCord, 2005). As boys usually demonstrate higher levels of conduct problems than girls, this pattern might lead to sex effects, especially in single-sex groups (e.g., Pössel et al., 2008).

None of these potential explanations gives us an unambiguous answer to our question, as all support contradictory sex effects. Thus, all research to examine possible explanations for sex effects can be only exploratory. A simple but effective strategy for testing these potential explanations is to measure both sexes' knowledge about the content of a prevention program after participation. If Shatté's (1996) explanation is correct-that boys find the cognitive elements of programs more appealing whereas girls prefer the social elementsboys should be more knowledgeable about cognitive elements, whereas girls should be more knowledgeable about social elements. If Shatté (1996) is correct that group leaders push more boys into tasks than girls, then boys should generally be more knowledgeable about constituent program parts independent of the content of the program. However, if girls are more motivated to master trained skills and have more opportunities to apply them (Gillham et al., 2006), they should generally be more knowledgeable about the content of a prevention program than boys. If different levels of conduct problems lead to sex effects, both sexes should differ in this variable at baseline.

To test these different possible explanations for sex effects in prevention programs, we used existing but unanalyzed 12-month follow-up data from the present study that demonstrated a sex effect in its 6-month follow-up (reference omitted for blind review). We 
would like to point out that the study was designed to examine the proposed inverse U-shape of effects on adolescent depressive symptoms but not a sex effect.

\section{Hypotheses}

The present study investigated the course and magnitude of effects of the prevention program LARS\&LISA (reference omitted for blind review) on adolescent depressive symptoms over 12 months post-intervention. Based on previous studies, we hypothesized that the magnitude effects of the prevention program would increase from post-intervention to 6-month follow-up and later decline to 12-month follow-up.

In addition, the present study exploratored possible explanations for sex effects in the prevention of depressive symptoms in adolescents. Based on the contradictory empirical data about sex effects found in the literature, we hypothesized that sex effects are not based on sex itself but on conduct problems at baseline and/or participant's knowledge about the cognitive and social content of the prevention program. To be able to test possible explanations for sex effects, we needed to find positive effects of the prevention program that distinguished between both sexes. Therefore, another aim of the present study was to replicate the sex effects of the depression prevention program in a 12-month follow-up. Based on the results of an earlier publication using the same sample but drawing on data from a 6-month followup only (reference omitted for blind review), we expected that girls would benefit more from participating in the prevention program than boys in the 12-month follow-up. As contradictory data exist for all of the hypotheses mentioned above, it seems likely that knowledge of the prevention program's content and conduct problems are only partly responsible for sex effects. As these variables were not considered in earlier prevention studies and the current study was not designed to test this question, this part of the study had an exploratory focus.

\section{Methods}




\section{Participants}

A total of 301 adolescents participated in the present study, which was conducted in four middle schools in the area of Tübingen (southwest Germany). Although data on the socioeconomic status of the students were not available, a wide range of social classes were likely represented because participating students were located in schools in economically diverse regions of the area. In the German school system, established classes of up to 30 students take all of their school courses together during the entirety of their high school education. The intervention group, who received the LARS\&LISA prevention program, consisted of 163 students (72 girls) in six of these school-cohort classes. The nonintervention control group, who received academic lessons as usual, was composed of 138 students (68 girls) in six other school-cohort classes. The mean age of participants in the intervention condition was 13.73 years $(S D=0.63)$, and the mean age in the control condition was 13.63 years $(S D=0.58)$. The age range of this sample is within the range of earlier studies with school-based prevention programs (e.g., Clarke et al., 1993; Petersen et al., 1997). During the course of the study, 25 out of the 163 intervention students and 17 out of the 138 control students dropped out because they changed schools (see Figure 1). There were no differences between the dropouts and the remaining students for either condition (intervention vs. control), $\chi^{2}(1)=0.57, p=.451$, sex, $\chi^{2}(1)=0.24, p=.625$, or age, $t(49.25)=$ $0.20, p=.839$. However, the dropouts showed more severe depressive symptoms, $t(299)=-$ $2.37, p<.019$, than the students who remained in the intervention or control conditions. There was no evidence for differences in the characteristics of dropouts by condition, sex: $\chi^{2}(1)=0.89 p=.346$; age: $t(40)=-1.41, p=.168$; severity of baseline depression: $t(40)=-$ $0.71, p=.480$. In addition, there were no significant difference in the characteristics of remaining students by condition, sex: $\chi^{2}(1)=0.36 p=.548$; age: $t(257)=-0.89, p=.375$; severity of baseline depression: $t(257)=-0.63, p=.530$. Further, while the age of remaining boys and girls was not significantly different, $t(257)=1.24, p=.217$, the depressive 
symptoms at baseline were more severe in remaining girls than in remaining boys, $t(257)=-$ $2.56, p=.011)^{2}$, which is consistent with epidemiological studies revealing that severity of depressive symptoms is higher in adolescent girls than in boys (Angold et al., 2002).

\section{Measures}

Self-Report Questionnaire - Depression. The Self-Report Questionnaire Depression (SBB-DES) is an instrument developed for children and adolescents that measures the severity of major depression and dysthymia symptoms outlined by DSM-IV and ICD-10 (Döpfner, Götz-Dorten, \& Lehmkuhl, 2008). The SBB-DES consists of 26 items (e.g., "I am sad most of the time."). Each item is answered using a 4-point Likert scale, with higher numbers indicating more accordance with the item $(0=$ Not at all, $1=A$ little bit, $2=$ Considerably, $3=$ Particularly). The test score is determined as the mean of the items, creating a range of scores from 0 to 3 . In our sample, Cronbach's alpha was $.92\left(\mathrm{CI}_{95}=.91\right.$ to 93; Barnette, 2005), which is comparable to internal consistencies of normative data for a representative German population (Döpfner et al., 2008). Further, the 6-month test-retest stability in our sample was $r(301)=0.56\left(\mathrm{CI}_{95}=.48\right.$ to .63$)$.

Knowledge-Test. We developed a self-report instrument to measure students' knowledge about the cognitive and social content of the prevention program used in the study. The Knowledge-Test consists of 5 multiple-choice items to measure cognitive content (e.g., "Which words are typical of action-blocking thoughts?") and 5 items to measure social content (e.g., "Which of the following is important in making contact with others?"). The items are in multiple-choice style with four responses for each question, including one correct answer. The test score is determined as the sum of correctly answered items, creating a range of scores from 0 to 5 for each of the two content categories. The correlation between cognitive and social items was $r=.27, p<.001$. The scores on the cognitive items of the

\footnotetext{
${ }^{2}$ To control for the sex differences in the depressive symptoms at baseline we calculated a linear model of the post-intervention, 6-month follow-up, and 12-month follow-up, using the baseline depression scores as control variable. The results of this analysis revealed the same pattern as the original analysis.
} 
Knowledge-Test exhibited an internal consistency of $\alpha=.53\left(\mathrm{CI}_{95}=.39\right.$ to .65$)$, for scores on the social items Cronbach's alpha was $.56\left(\mathrm{CI}_{95}=.47\right.$ to .64$)$, and the total Knowledge-Test scores had an internal consistency of $\alpha=.60\left(\mathrm{CI}_{95}=.52\right.$ to .67$)$ for our overall sample. Furthermore, the 6-month test-retest reliabilities for scores on the cognitive items, social items, and total scale were $r(301)=0.24\left(\mathrm{CI}_{95}=.12\right.$ to .35$), r(301)=0.44\left(\mathrm{CI}_{95}=.33\right.$ to .53$)$, and $r(301)=0.44\left(\mathrm{CI}_{95}=.33\right.$ to .53$)$, respectively.

Strengths and Difficulties Questionnaire. The Strengths and Difficulties Questionnaire (SDQ; Woerner et al., 2002) is a brief questionnaire that measures the psychological adjustment of 11- to 16-year-olds. The SDQ consists of 25 positive and negative attributes. Participants rate each item on a 3-point Likert scale describing their personal strengths and difficulties (on a scale ranging from $0=$ Not true, $1=$ Somewhat true, 2 $=$ Certainly true). The items are divided into 5 scales (emotional symptoms, conduct problems, hyperactivity, peer problems, prosocial behavior) of 5 items each. The sum scores for each scale range from 0 to 10 . The SDQ has been translated into more than 40 languages and differentiates between normal adolescents and those with pathological symptoms (Woerner et al., 2002). It also differentiates between different psychological disorders as well as the Youth Self Report (YSR; Achenbach, 1991) but with only a fifth of the items of the YSR (e.g., Klasen et al., 2000). In our sample, internal consistencies (Cronbach's $\alpha$ ) for the self-report scales of the SDQ were between $.63\left(\mathrm{CI}_{95}=.56\right.$ to .69$)$ and $.80\left(\mathrm{CI}_{95}=.76\right.$ to .83$)$, which are comparable to internal consistencies of normative data for a representative German population (Woerner et al., 2002). In our sample, the 6-month test-retest stability was $r(301)$ $=.50\left(\mathrm{CI}_{95}=.41\right.$ to .58$)$.

\section{The School-Based Prevention Program}

The manualized school-based universal primary prevention program LARS\&LISA (Pössel, Horn, Seemann, et al., 2004) is based on the social information processing model of social competence as described by Dodge (1993). This model distinguishes five stages of 
information processing: encoding, mental representation, response accessing, response evaluation and selection, and enactment. Evidence exists that depressed children have deficits in social information processing. For example, multiple cross-sectional studies found that higher levels of depressive symptoms are significantly associated with a more negative (Bell, Luebbe, Swenson, \& Allwood, 2009; Quiggle, Garber, Panak, \& Dodge, 1992) and less positive (Bell et al., 2009) social information processing style. Children with higher levels of depressive symptoms make more global, stable, and internal attributions; evaluate assertive behavior less favorably; and select more passive responses compared with children with low depression levels (Quiggle et al., 1992). In a longitudinal study with adolescents, Pössel, Seemann, Ahrens, and Hautzinger (2006) showed that depressive information processing significantly predicts depression assessed 1 year later.

LARS\&LISA is designed to address these social information processing deficits. Many of the methods used in the program are taken from cognitive-behavioral therapy (Beck, Rush, Shaw, \& Emery, 1979). The program targets cognitive and social components of the social information processing model as follows: (a) five cognitive sessions focus on understanding the relations among cognitions, emotions, and behaviors, and teach how to identify and challenge negative cognitions; and (b) four social sessions train participants in assertiveness and social competence. Each part of the program is designed to address stages of the social information processing model (Dodge, 1993) and to improve knowledge and skills.

Cognitive component. The cognitive component of the program is related to Dodge's (1993) stages of mental representation, response accessing, and response evaluation and selection. In the mental representation stage, information encoded from social situations is stored within short-term memory. Depressed individuals in this stage tend to interpret negative events as global and stable (Abramson, Alloy, \& Metalsky, 1989). LARS\&LISA is designed to decrease underlying negative cognitions and to increase more accurate appraisals. 
The cognitive component of LARS\&LISA seeks to alter adolescents' information processing through the development of more accurate beliefs, which then will result in less negative emotions (Beck et al., 1979). Thus, adolescents in this program are expected to show less sadness and anger when confronted with negative events, such as academic failure or social rejection. Regarding the response evaluation and selection stage, the cognitive components of the program teach students to re-evaluate their appraisals of the consequences of their behaviors as they learn to evaluate the acceptability and results of their actions. This training is especially useful for adolescents vulnerable to depression, who often select social withdrawal as the least negative option compared with aggression or assertiveness. Finally, adolescents' self-efficacy in social interactions increases due to the development of more accurate and functional cognitions and behaviors. They practice engaging in social transactions and learn to select such response options as an alternative to withdrawal.

Social component. The social component of the program involves training in assertiveness and building social competence and is linked with the information processing stages of (a) response accessing, (b) response evaluation and selection, and (c) enactment. In regard to response accessing, LARS\&LISA provides training in new or unfamiliar functional behaviors such as assertiveness through role plays that lead to adolescents' increased recognition of the feasibility of these more adaptive behaviors. In the response evaluation and selection stage, positive reinforcement during role plays encourages adolescents' favorable evaluations of their behaviors both inside and outside the context of the program. Functional behavior also occurs in the enactment stage, which represents individuals' actual verbalizations, motor activities, autonomic activity, and other responses. By learning increasingly adaptive social behaviors, adolescents develop, expand, and improve their use of their social networks.

Additionally, LARS\&LISA includes a motivation section (one session), which represents an improvement made on a previous iteration of the program (LISA-T; Pössel et 
al., 2005; Pössel, Horn, Hautzinger et al., 2004). This section gives students an opportunity to consider their goals and how they plan to achieve them. Based on these principles, the usefulness of the newly acquired skills is shown at the end of every session. This procedure was developed in accordance with Kanfer and Gaelick-Buys (1991) and was adapted to adolescents. All parts of the program use illustrative situations introduced by the participating adolescents.

\section{Design and Procedure}

The impact of the LARS\&LISA prevention program on depressive symptoms was determined through a prospective design comparing intervention and control conditions. Students and their teachers completed all questionnaires at baseline, immediately following intervention, and during 6-month and 12-month follow-ups. The only exception was the Knowledge-Test, which was administered only during the post-intervention, 6-month followup, and 12-month follow-up assessments. LARS\&LISA was administered once a week over a 10-week period during regular school hours. Each session was composed of two 45-minute class periods for a total of 1.5-hours per session. During this time, the control classes attended their usual academic lessons. Because of this design, adolescents and teacher knew about the assignment of the students to the intervention or non-intervention control group.

Letters were sent to the principals of six middle schools in the area of Tübingen (southwest Germany) asking for their school's participation in this project. The principals of two of the six schools refused to participate due to concerns about the potential loss of academic teaching time. A written description of the study was sent to the parents of all eighth-grade students at the four participating schools. Additionally, the study was described in detail to some of the students and their parents during a parent-teacher conference conducted by the researchers. In these conferences, the adolescents, parents, and their teachers discussed class participation and decided together if the class as a whole should participate in the study. As a result of this procedure, all classes invited to participate in the 
study decided to participate in the study. Furthermore, all parents and adolescents who did not participate in the parent-teacher conferences also agreed to participate in the study. This very high participation rate is typical for universal prevention programs in a school system like Germany’s (Pössel et al., 2005; Pössel, Horn, Hautzinger et al., 2004) that has a schoolcohort system in which a class of students become a cohort within the school, taking all their high school courses together. Students commonly have most of their friends in one class and are thus highly motivated to participate in the same activities, independent of the context of these activities. This holds true for participation in prevention programs.

Within participating schools, classes at the eighth-grade level were randomly assigned to intervention and control groups. Both intervention and control conditions were recruited in each school so that at least one class was randomly assigned to one condition and another class was automatically assigned to the other. In schools with more than two eighth-grade classes, these classes were stratified across schools to have the same number of classes in both conditions.

Separate intervention classes were conducted by sex because adolescents may be hesitant to portray themselves authentically in front of peers of the other sex. In fact, for boys, research has shown that sex-homogeneous groups can create contexts in which boys can share feelings and emotions without embarrassment (Sukhnandan, Lee, \& Kelleher, 2000), be less distracted, and be more open and responsive without fear of compromising their "laddish" image in front of girls (Warrington \& Younger, 2003). Furthermore, a pilot study has shown that adolescents in this age group work more effectively and openly as a team if they participate in same-sex groups (Pössel et al., 2003). The median group size in the intervention condition was 14 adolescents per group $(M=13.96 ; S D=2.16$; Range $=8$ to 18$)$ with boys comprising $19.2 \%$ of students in groups with 14 or fewer participants ( 1 of 6 groups) and $85.6 \%$ in groups with at least 14 participants (5 of 6 groups). The mean intervention group size for boys was $15.15(S D=1.70$; Range $=13$ to 18$)$, and the mean 
intervention group size for girls was $12.46(S D=1.69$; Range $=8$ to 14$)$. In addition, the difference in mean intervention group size between boys and girls was significant, $t(161)=$ $10.07, \mathrm{p}<.001$, with boys being in larger groups than girls.

Each intervention group was coached by a group leader and a co-leader, who were either master's level psychologists or graduate students experienced in working with adolescents. As the majority of the eight group leaders and co-leaders were female (63\%), it was not possible to fit their sex to the sex of the adolescents. To minimize effects of the leader's sex, group leaders and co-leaders worked in mixed-sex teams. Training was provided for all group leaders in three steps. First, all potential group leaders went through the program as participants. For this step of the training, the group leaders met as a group for 1.5 hours five days a week for two weeks. Secondly, each studied the manual, all materials and procedures, and resolved unclear points with the first author. Finally, each led a group as a co-leader together with a more experienced leader. Furthermore, group supervision was provided for all group leaders with the help of video recordings of each session and a 1.5hour weekly meeting with the first author. These recordings also were used to ensure that group leaders adhered to the LARS\&LISA manual. The study was approved by the ethical committee of the German Psychological Association.

\section{Data Analysis}

Interactions between students in the same class or school may lead to the intercorrelation of variables and nonindependence of data and create a general methodological problem in school-based studies (Hopkins, 1982; McCoach \& Adelson, 2010). Disregarding potential nuisance variables may lead to misinterpretations of the results because natural groups, such as classes (as well as reciprocal influences between individuals and groups), can lead to enhanced group-specific differences between individuals (Goldstein, 1995). Therefore, to investigate differences in changes in depression scores over time, we conducted a series of 3-level hierarchical linear model (HLM) analyses using HLM version 
6.08 (Raudenbush, Bryk, Cheong, Congdon, \& du Toit, 2004). In these models, time points were nested in students, and students were nested within classes (either their homogeneous intervention group or their regular classroom for control students). Because both experimental conditions were administered in each participating school, school was not considered a group variable. The dependent variable of interest was depression score, which was measured at baseline (time $=0$ months), post-intervention (time $=3$ months), at 6-month follow-up (time $=9$ months), and at 12-month follow-up (time $=15$ months). Although 25 out of 163 intervention students and 17 out of 138 control students dropped out during the course of the study, the data of 163 intervention students and 136 control students were included in the analyses as they participated in assessments at one time point or more (see Figure 1). This was possible due to the use of HLM with maximum likelihood estimation, which incorporates all participants observed at least once on the outcome (Raudenbush \& Bryk, 2002). Because students without 12-month follow-up knowledge data would be eliminated from the analyses, drop-out was due to moving away from the school rather than related to knowledge, and we were not estimating changes in knowledge over time in the model, we used last observation carry forward (LOCF) for the $14 \%$ of students with missing data on the knowledge variables; however, we did not do this with the depression measure.

Based on graphs of individual growth and preliminary analyses, we found that change in depression from baseline to the 12-month follow-up had a different trajectory for boys and girls. While the change in depression for boys followed a linear trajectory, the change in depression for girls followed a quadratic trajectory. Given that a quadratic model is more general than a linear model, we modeled a quadratic model with boys as the reference group. We included both a linear and quadratic measure of time, in months. Although the intercept (depression at time 0$)$ varied across individuals $(p<.001)$, it did not vary across groups $(p>$ $.500)$, meaning that the groups did not differ in their average depression at baseline. This was expected given that classes within the same schools were randomly assigned to intervention 
or control. Therefore, we fixed the intercept to be the same across all groups. Because we were interested in whether the growth trajectories differed by intervention group, we allowed the growth parameters (linear and quadratic) to randomly vary across individuals and across groups. Given the graphs revealed different trajectories for boys and girls and that research has found sex differences in the effect of intervention, we included sex as a predictor of the intercept, linear rate of increase, and rate of acceleration. Because 12 (intervention condition groups) of the 18 groups were single-sex (the other 6 groups were co-ed control group classes), not permitting estimation of a slope for the effect of sex within group, we did not allow the effect of sex to vary across groups. We included intervention as a predictor of linear growth, and then given the fact that only girls had a quadratic growth, we included an intervention $\mathrm{x}$ sex interaction as a predictor of quadratic growth.

\section{Results}

\section{Baseline Comparisons}

No significant differences between the conditions were found for age, boys: $t(159)=-$ $0.65, p=.518$; girls: $t(138)=-1.36, p=.176$; self-reported depressive symptoms at baseline, boys: $t(159)=0.19, p=.851$; girls: $t(138)=-1.75, p=.082$; conduct problems at baseline, boys: $t(118.57)=1.54, p=.127$; girls: $t(138)=1.00, p=.319 ;$ and sex, $\chi^{2}(1)=0.78, p=$ .376. Given that the difference between baseline depression in girls had the smallest $p$ value, we examined whether there was a cross-level interaction between sex and treatment in the intercept (baseline depressive symptoms) in the multilevel model that accounted for the clustered data. The differential in self-reported depressive symptoms at baseline between girls in the control group and girls in the intervention group was $0.02(\mathrm{SE}=0.10, p=.855)$. Therefore, given the sample size and number of parameters being estimated, we maintained a more parsimonious model and did not model an interaction between baseline depression, sex, and condition. It is of further interest that depressive symptoms and conduct problems reported by the participants cover almost the whole range of the scales (depression score: 0.00 
to 2.50; conduct problems: 0 to 9). These data indicate the representation of depressive symptoms and conduct problems on all severity levels in the sample. Finally, while no data were collected to students' knowledge at baseline, no sex differences in cognitive, $t(127)=-$ $0.36, p=.721$, social, $t(127)=-1.36, p=.183$, or total knowledge, $t(127)=-1.17, p=.246$, were found in the control group at post-intervention, the time point least likely to be affected by diffusion of information.

The descriptive statistics are shown in Table 1 . The test-retest reliability of selfreported depression $(r=.45$ to $.56 ; p s<.01)$ and composite externalizing problems $(r=.38$ to $.50 ; p \mathrm{~s}<.01$ ) from post-intervention to 12 -months follow-up is relatively high. Further, as we would expect, the correlations between baseline depression and depression at the other time points seems numerically lower $(r=.22$ to $.53 ; p s<.01)$. The correlations of total knowledge with cognitive and social knowledge at any given time point are .76 to .89 ( $p$ s < .01 ) while the correlations between cognitive and social knowledge at the same time point are only .27 to $.52(p s<.01)$ and the correlations between total knowledge across time points are .40 and $.42(p s<.01)$. Further, the correlations between self-reported depression and composite externalizing problems ranges between $r=.17$ and $.34(p<.05)$. While not always significant, the correlations between self-reported depression and (cognitive, social, total) knowledge about the content of the prevention program correlate consistently negative $(r=-$ .04 to -.31). The same is true for correlations between the composite externalizing problems and knowledge $(r=-.10$ to -.27$)$.

\section{Long-term Effects of Prevention Program by Sex}

As shown in Table 2, there were no sex differences in depression scores at the initial time point, but there were sex differences for the linear and quadratic growth parameters $(p<$ .05). Although there was no intervention effect on the linear rate of increase, there was an effect of intervention on girls' rate of acceleration $(p<.05)$, indicating that the rate of acceleration for girls in the intervention group was significantly lower than the rate of 
acceleration for girls in the control group. The effect size for this parameter (the effect of the intervention on girls' rate of acceleration, or the intervention by sex interaction effect on the rate of acceleration) can be calculated by dividing the parameter by the population standard deviation of the quadratic trend (the polynomial trend of interest; Raudenbush \& Liu, 2001), which equals $\delta=\frac{-0.001197}{0.00206}=-0.58$. This effect is moderate (Cohen, 1992).

The effect of the intervention on girls' depression is best demonstrated using modelpredicted values, which are plotted on Figure 2. Although the model-predicted depression scores for both intervention and control girls at baseline were 0.63 and the model-predicted depression scores essentially did not differ post-intervention, at the 6-month follow-up the differential was predicted to be 0.07 , and at the 12-month follow-up it was predicted to be 0.23. This indicates that although the control group did experience a natural drop in depression post-intervention, by the 12-month follow-up, their depression had risen above their baseline. However, the intervention moderated that effect, resulting in the intervention group not only maintaining but increasing their decrease in depression following the intervention. These model-based predicted values are supported by the actual group means, which consistently decreased from each time point to the next for the intervention group but for the control group increased slightly from post-intervention to 6-month follow-up and increased drastically from the 6-month follow-up to the 12-month follow-up, with average depression being higher at that point than baseline. As shown in the figure, boys began with lower depression scores than girls but then both control and intervention boys' depression scores increased during the intervention and from post-intervention to 6-month follow-up, with their 12-month follow-up scores being slightly above those of the control girls. The differences between the control and intervention boys were not statistically significant.

To examine the intervention's effect in reducing symptoms for adolescents whose baseline depression score was in the clinically depressed range for their age, we re-ran the 
intervention effect model with only this subgroup. Again, we found evidence of an intervention-by-sex interaction, with girls but not boys in the prevention condition demonstrating reduced depressive symptoms over time, $-0.003, \mathrm{t}(72)=-2.47, p=.016$.

\section{Possible Explanations for Sex Effects}

Finally, we were interested in whether the relationship between other variables and change in depression may be leading to an intervention effect for girls and not for boys. Therefore, we added conduct problems at baseline, cognitive knowledge, social knowledge, and total knowledge (sum of cognitive and social knowledge) at 12-month follow-up, and an interaction between each variable and sex to the model as separate covariates related to the rate of acceleration. We kept in the intervention-by-sex interaction affecting the rate of acceleration but removed the non-significant intervention effect from the linear rate of change.

Because boys had higher baseline conduct scores ( 0.59 points higher than girls, $\mathrm{t}(240)$ $=-2.83, p<.01$ ), we first tested the effect of baseline conduct scores. As shown in Table 3, we found that baseline conduct problems were not a significant predictor of the rate of acceleration for boys $(p=.61)$ and that there was not a differential in that effect between boys and girls $(p=.80)$. After controlling for conduct problems and sex-by-conduct problems interaction, the intervention effect on girls' rate of acceleration remained significant $(p=.03$, $\delta=-0.47)$, in favor of the intervention group.

Next, we tested the relationship between cognitive knowledge at 12-month follow-up and change in depression. Despite Shatté's prediction (1996) that cognitive components of prevention programs appeal more to boys, girls actually had higher cognitive scores at 12 month follow-up $(0.28$ points higher than boys, $t(206)=2.93, p<.01)$. This indicated that although boys and girls had similar knowledge at post-intervention, $t(127)=-0.36, p=.721$, the girls exhibited greater knowledge over the course of a year. Moreover, we chose 12month follow-up rather than post-intervention or 6-month follow-up as that time point 
reflected the amount of knowledge retained and even gained post intervention, which would be the most likely to relate to change in depression over time. Also, using 12-month followup was appropriate as we were examining the longer duration of effects of the intervention program compared to other similar cognitive behavioral programs. As shown in Table 3, 12 month follow-up cognitive knowledge was significantly related to boys' rate of acceleration $(p<.001)$, with boys who had greater 12-month follow-up cognitive knowledge having a lower rate of acceleration in depression compared to boys who had less 12-month follow-up cognitive knowledge. There also was a significant sex-by-cognitive knowledge interaction ( $p$ $=.02$ ) that indicated that girls did not receive as great of a benefit for greater 12-month follow-up cognition. After controlling for cognitive knowledge at 12-month follow-up, both the sex differential for the rate of acceleration $(p=.008)$ and the intervention-by-sex interaction affecting the rate of acceleration remained significant $(p=.04, \delta=-0.44)$. As a post-hoc analysis, we reverse-coded the sex dummy code to examine the relationship between 12-month follow-up cognitive knowledge and change in depression for females, controlling for treatment. Although girls exhibited greater cognitive knowledge than boys, after controlling for treatment, there was not a significant relationship between 12-month cognitive knowledge scores and the rate of acceleration for girls $\left(\gamma_{220}=-0.006, S E=0.0003, p=.128\right)$.

Consistent with Shatté's (1996) prediction, we found that at 12-month follow-up, girls had higher social knowledge than boys (difference of .33 points, $t(207)=2.95, p<.01$. Social knowledge at 12-month follow-up was significantly related to the rate of acceleration for boys ( $p=.002$; as shown in Table 3), with boys who had greater 12-month follow-up social knowledge having a lower rate of acceleration in depression. There was not a significant sex-by-social knowledge interaction $(p=.12)$, indicating that social knowledge at 12-month follow-up had a similar relationship to girls' rate of acceleration in depression. Similar to the model controlling for 12-month follow-up cognitive knowledge, in the model controlling for 12-month follow-up social knowledge, both the sex differential for the rate of 
acceleration $(p=.011)$ and the intervention-by-sex interaction affecting the rate of acceleration remained significant $(p=.04$, $\delta=-0.46)$ As a post-hoc analysis, we reversecoded the sex dummy code to examine the relationship between 12-month follow-up social knowledge and change in depression for females, controlling for treatment. Although girls exhibited greater social knowledge than boys, after controlling for treatment, there was not a significant relationship between 12-month social knowledge scores and the rate of acceleration for girls $\left(\gamma_{220}=-0.003, S E=0.0003, p=.315\right)$.

Given that girls had higher social and cognitive knowledge, we also tested the relationship of total knowledge at 12-month follow-up with change in depression. Similar to the findings for cognitive knowledge, total knowledge at 12-month follow-up had a significant $(p<.001)$ relationship to the rate of acceleration for boys (see Table 3 ). However, that differential was moderated by sex, with girls' rate of increase not decreasing as much as boys' did $(p=.049)$. Although after controlling for combined cognitive and social knowledge at 12-month follow-up was still a sex difference in the rate of acceleration $(p=.008)$, but there was only a marginally significant intervention-by-sex interaction affecting the rate of acceleration $(p=.071)$, although the effect size was still moderate $(\delta=-0.41)$. Even after controlling for 12-month follow-up knowledge, there was significant variability left to be explained in changes in depression between the groups, suggesting that other variables might explain the intervention effect above and beyond knowledge. As a post-hoc analysis, we reverse-coded the sex dummy code to examine the relationship between 12-month follow-up total knowledge and change in depression for females, controlling for treatment. Although girls exhibited greater total knowledge than boys, after controlling for treatment, there was not a significant relationship between 12-month total knowledge scores and the rate of acceleration for girls $\left(\gamma_{220}=-0.004, S E=0.0002, p=.098\right)$. 
Thus, similar results, with effect sizes for the intervention-by-sex interaction after controlling for 12-month follow-up knowledge ranging from -0.41 to -0.46 , were obtained for cognitive, social, and total knowledge but with total knowledge having the smallest effect size and having only a marginally significant effect for the intervention-by-sex interaction. As noted, females had significantly more cognitive, $0.32, t(205)=3.37, p=.001$, social, 0.41 , $t(205)=4.24, p<.001$, and total knowledge, $0.73, t(205)=4.70, p<.001$, at 12 -month follow-up. However, although there was a relationship between knowledge and rate of acceleration in depression for boys, this same relationship did not exist for girls, after accounting for treatment. Additionally, total knowledge in girls in the intervention condition increased from post-intervention to 12 -month follow-up, $t(57)=3.60, p=.001$, while total knowledge remained stable over time in intervention condition boys, $t(71)=0.58, p=.560$. Finally, as we would expect, students in a intervention group had significantly more cognitive, $0.23, t(16)=2.40, p=.029$, social, $0.49, t(16)=5.08, p<.001$, and total knowledge, $0.72, t(16)=4.64, p<.001$, at 12 -month follow-up. The interaction between knowledge and sex is evident when comparing students in the intervention groups with their peers of the same sex in the control groups. Although boys in the intervention groups generally did not have greater knowledge than boys in the control group [cognitive: $t(156)=$ $0.59, p=.55$; social: $t(156)=2.02, p=.05$; total: $t(156)=1.55, p=.12]$, girls in the intervention group consistently exhibited greater knowledge than their peers in the control group [cognitive: $t(137)=2.69, p=.01$; social: $t(137)=4.23, p<.001$; total: $t(137)=4.54, p$ $<.001]$. After accounting for sex and intervention, the unexplained variance between groups at 12-month follow-up was not significant for cognitive knowledge, $\tau_{00}=0.00012, \chi^{2}(16)=$ $13.25, p>.500$, social knowlege, $\tau_{00}=0.00004, \chi^{2}(16)=6.35, p>.500$, or total knowledge, $\tau_{00}=0.00017, \chi^{2}(16)=10.27, p>.500$.

\section{Potential Confounder: Group Size}


As mentioned previously, the mean intervention group size was significantly different for boys and girls, with boys being in larger groups than girls, $t(161)=10.07, \mathrm{p}<.001$. Therefore, the researchers conducted some analyses to examine whether it was possibly group size rather than sex leading to the intervention effects. Although we cannot include sex, group size, and intervention in one model due to multicollinearity, we can examine subsets of those variables. Controlling for sex, large groups did not experience significantly more linear growth, $t(16)=0.20, p=.85$, or a significantly different quadratic change in growth, $t(16)=$ $0.01, p=.95$, in depressive symptoms. Moreover, while females have significantly more knowledge at 12-month follow-up, $0.66, t(204)=3.72, p<.001$, and as we would expect, students in a intervention group have significantly more knowledge, $0.62, t(15)=3.32, p=$ .005 , after controlling for sex and intervention, students in smaller groups do not, on average, have significantly more knowledge, $0.22, t(15)=0.09, p=.393$. Given that the groups did not differ in their change in depression after accounting for sex and that smaller group size did not predict 12-month follow-up knowledge of intervention content above and beyond sex and intervention, concerns about the role of group size as a confounder were reduced.

\section{Discussion}

The purpose of the present study was twofold. First, the course and magnitude of effects of the prevention program LARS\&LISA on adolescent depressive symptoms over 12 months post-intervention were evaluated. Based on previous studies, we hypothesized that the magnitude effects of the prevention program would increase from post-intervention to 6month follow-up and later decline to 12-month follow-up. Second, we expected to find that the effects of the prevention program differed by sex. Based on the results of an earlier publication using the same sample but drawing on data from a 6-month follow-up only (reference omitted for blind review), we expected that girls would benefit more from participating in the prevention program than boys would in the 12-month follow-up. If those differential effects were found, we planned to explore possible explanations of sex effects in 
prevention of depressive symptoms in adolescents. Based on the contradictory empirical data about sex effects found in the literature, we hypothesized that sex effects are not based on sex itself but on conduct problems at baseline or on participant's 12-month follow-up knowledge about the cognitive and social content of the prevention program. However, the study was not designed to answer this question. Thus, the second tests for possible explanations of sex effects are exploratory in nature.

Consistent with previous research (Garber, Keiley, \& Martin, 2002; Hankin et al., 1998), change in depressive symptoms had a different trajectory for both sexes. Change in depressive symptoms for boys followed a linear trajectory. As expected, we did not find effects of the prevention program on depressive symptoms in boys. Change in depressive symptoms for girls, however, followed a quadratic trajectory. Further, we found that depressive symptoms in girls in the intervention condition not only did not increase over time but the symptoms even decreased over time through the 12-month follow-up. On the other hand, the depressive symptoms in girls in the control condition decreased slightly during the 3 months that the intervention girls were in the program but then became increasingly more severe leading to the 12-month follow-up, with average depressive symptoms being more severe at the 12-month follow-up than baseline. There was very little difference in the depressive symptoms between girls in the intervention and control condition caused by these different trajectories at post-intervention, but the difference increased at the 6-month followup. Moreover, the difference unexpectedly was even greater at the 12-month follow-up. The different rates of acceleration for the intervention and control girls had a moderate effect size (Raudenbush \& Liu, 2001). Thus, the long-term effects of LARS\&LISA on depressive symptoms were better than expected. Not only did the effects last longer than expected, but the natural increase of the severity of depressive symptoms in girls could be reversed.

This result raises the question why the effects of LARS\&LISA have a longer duration than other similar cognitive behavioral prevention programs. One possible explanation might 
be the integration of a motivation section based on Kanfer and Gaelick-Buys' (1991) selfmanagement approach into LARS\&LISA. It is well established that adolescents currently experiencing depressive symptoms are more motivated to actively take part in a program than students that do not have problems (Jaycox, Reivich, Gillham, \& Seligman, 1994; Offord, 2000). Thus, it is likely that adolescents without depressive symptoms at baseline are less motivated to master trained skills. This hypothesis is supported by prevention studies revealing that adolescents with depressive symptoms at baseline benefit more from universal prevention than youths without depressive symptoms at baseline (Horowitz, Garber, Ciesla, Young, \& Mufson, 2007). The average lengths of a depressive episode in adolescents is between a few months and 9 months (for an overview see Groen, Pössel, \& Petermann, 2003), Thus, it can be expected that the effect of a prevention program fades out in about the same time frame. This is the case as the depressive symptoms in the group that actively participated in the program - because it was motivated by elevated depressive symptoms - are reduced at that time while other adolescents - which did not spent much attention during the program - might develop depressive symptoms. The motivation section in LARS\&LISA is designed to motivate every adolescent participating in the program by demonstrating to every student - independent of their baseline level of depressive symptoms - to see the usefulness of the trained skills for their everyday life. To test this hypothesis, future research should compare the long-term effects of cognitive-behavioral universal prevention programs with and without elements of Kanfer and Gaelick-Buys' (1991) self-management approach.

Another explanation for the longer-lasting effects might be not the program itself but the school-cohort system in German schools and the fact that students commonly have most of their friends in one class. It is possible that the prevention program is so effective because students talk with their friends about the content of the program even between the postintervention and the 12-month follow-up assessments. In addition, the program might promote interpersonal relationships by allowing the adolescents to share more personal 
thoughts with each other in smaller and more protected groups (Sukhnandan et al., 2000). Thus, the improved interpersonal relationships may have helped the adolescents to cope with stressors that came up in the follow-up time. This hypothesis is consistent with a previous study that found that participation in LISA was associated with an increase in the frequency of reliance on social support in girls and an increase of self-reported social network in boys from baseline to post-intervention (Pössel et al., 2003). A study that allows testing this hypothesis is currently underway, controlling for these nonspecific change mechanisms by comparing a cognitive-behavioral prevention program with a structurally equal program that does not apply cognitive-behavioral interventions.

To explore possible explanations for sex effects of prevention programs, we tested for conduct problems at baseline and participant's 12-month follow-up knowledge about the cognitive and social content of the prevention program. Although boys reported more conduct problems than girls at baseline, conduct problems did not change the intervention-bysex interaction effect on the severity of depressive symptoms. Contrary to Shatté's (1996) hypothesis, although boys and girls had comparable knowledge at post-intervention, girls had more knowledge of both the cognitive and social content of the prevention program at 12 month follow-up than boys. Additionally, in girls participating in the prevention program, total knowledge increased from post-intervention to 12-month follow-up while total knowledge in their male peers remained stable over time. Interestingly though, cognitive knowledge and total knowledge decreased boys' rate of acceleration significantly more than girls' rate of acceleration. Nevertheless, both sexes benefited similarly from more social knowledge. Cognitive and social knowledge of the prevention program's content at 12month follow-up did not change the intervention-by-sex interaction effect on depressive symptoms. However, the combination of cognitive and social knowledge did reduce the intervention-by-sex interaction, resulting in a smaller, although still moderate effect size. Further girls benefitted more than boys knowledge-wise; however, knowledge was not related 
to girls' rate of acceleration. In addition, after controlling for total knowledge, the reduction of the intervention effect in girls seems only trivial (increase in $p$-value from $p=.04$ to $\mathrm{p}$ $=.07)$. Further, it is not only problematic that knowledge was not measured prior to intervention but also that knowledge and depression were measured at the same time (12month follow-up). Thus, it can not be absolutely excluded that girls in the intervention condition already knew more about the content of the cognitive-behavioral program than boys in the same condition. Nevertheless, the finding that boys and girls in the control condition at post-intervention, the time point least likely to be affected by diffusion of information, did not differ in their knowledge regarding cognitive, social, and total content of the program makes this unlikely.

Given the lack of definitive evidence for the source of the sex differences in the intervention effects, some further possible explanations are discussed here. First, girls know more than boys about the cognitive and social content of LARS\&LISA 12 month after the end of the prevention program. This finding is contradictory to Shatté's (1996) hypothesis that boys find cognitive elements like the logical dissection of emotions based on cognitive theories more appealing than girls. Instead, this result is consistent with educational research demonstrating that girls show more self-discipline than boys, which has been found to mediate the relationship between sex and overall GPA (Duckworth \& Seligman, 2006). In addition, girls are usually more mastery-oriented than performance-oriented in their learning strategies (Meece \& Holt, 1993), which leads to larger homework efforts and better grades (Kenney-Benson, Pomerantz, Ryan, \& Patrick, 2006). Both more self-discipline and more mastery-orientation could explain the finding that girls know more about the cognitive and social content of the prevention program. Further, the finding is consistent with Gillham et al.'s (2006) hypothesis that girls may be more motivated to learn the contents of a prevention program because they experience more stressful life events (Ge, Conger, \& Elder, 2001; 
Hankin \& Abramson, 2001) and are more likely to develop depressive symptoms (Angold et al., 2002) in puberty than boys.

In addition, it is possible that girls benefit more from the motivation section newly integrated into the prevention program. However, that is unlikely for at least two reasons. The theoretical reason to integrate this session was to motivate adolescents that have no problems at the beginning of the program. As the analyses demonstrate, girls remaining in the program are more severely depressed than boys at baseline. Thus, it would be expected that boys benefit more from the motivation session. This theoretical consideration is supported by an empirical study that demonstrated that boys benefit more from selfmanagement training to increase mathematics performance in elementary school children (Atkins \& Rohrbeck, 1993). Nevertheless, differences in the sample (children vs. adolescents) and outcome variable (math performance vs. depressive symptoms) might limit the generalizability of Atkins and Rohrbeck's (1993) results to our findings.

Second, because, so far, no dismantling study tested the importance of cognitive restructuring and social skills for the prevention of depression, the effect found for knowledge of both elements of the prevention program is the first hint that both elements are important for the effects of a prevention program. This is important as prevention researchers are under pressure to provide shorter programs that fit better into the busy school schedules. Naturally, focusing on cognitive restructuring or social skills would be the easiest way to shorten the existing prevention programs. Because of the importance of this issue, dismantling studies should follow up on this result before final conclusions are drawn.

The significant differences in depressive symptoms between girls and boys at baseline can be seen as another possible explanation for the sex effect benefiting girls. However, an analysis controlling for baseline depression found basically the same result pattern making it unlikely that higher motivation (Gillham et al., 2006) or regression to the mean might explain the sex effect. 
Another possible explanation for the sex effect is the school-cohort system in German schools and the fact that students commonly have most of their friends in one class. As mentioned above, it is possible that students talk with their friends about the content of the program even between the post-intervention and the 12-month follow-up assessments and that the program might promote interpersonal relationships. As girls are more communicative and depend more on interpersonal relationships (Nolen-Hoeksema \& Girgus, 1994), this nonspecific change mechanisms could explain why girls benefit more than boys. In addition, girls talking more with their friends about the content of the prevention program than boys, is consistent with the finding that knowledge about the program content increases in girls but remains stable in boys. Further, a previous study found that participation in LISA was associated with improvements in social relationships in both sexes (Pössel et al., 2003). So far, no study has tested for changes in the interpersonal relationships as possible explanation for sex effects. One study, however, unsuccessfully tested changes in social networks as mediator of the effects of a cognitive-behavioral prevention program on depressive symptoms (Pössel et al., 2005). Thus, while further research on unspecific change mechanisms like improved interpersonal relationships or communication about the content of prevention programs between participants as explanation of sex effects is necessary, it seems unlikely that these factors cause the sex effects in the prevention literature.

A final possible explanation for the sex effect might be that differences in social information processing between boys and girls exist and cause differences in the effects of LARS\&LISA. Many studies found that certain parts of the social information processing are more likely to be depressogenic in adolescent girls than in their male peers (see for a review Nolen-Hoeksema, 2006). However, there are only a few studies about possible sex differences in the associations between social information processing and depressive symptoms (Bell et al., 2009, study 1; Goldstein, 2006; Pössel \& Thomas, 2010; Stone, Gibb, \& Coles, 2010). Three of these studies focused exclusively on the stage of mental 
representation in adults. Using inference style (including causes, consequences, selfcharacteristics, Goldstein, 2006; Stone et al, 2010) and the cognitive triad (Pössel \& Thomas, 2010), respectively, as outcome variables, all three studies found an association between mental representation and depressive symptoms in women but not in men. The only study exploring all stages of social information processing in preadolescent children did not find evidence for such sex differences (Bell et al., 2009, study 1). As no previous study of the former version of LARS\&LISA tested for sex effects (Pössel et al., 2005; Pössel, Horn, Hautzinger et al., 2004), this line of research does not provide evidence for or against sex differences. Thus, it cannot be excluded that sex differences in the association between social information processing and depressive symptoms are associated with sex effects in our study. When interpreting the results of this study certain limitations of the presented study should be considered. The most important limitation is the absence of any formal intervention as control condition. Although this is very common in prevention research (e.g., Clarke et al., 1993; Gillham, Reivich, Jaycox, \& Seligman, 1995), this problem should not be neglected. Thus, it is unclear whether the reduction of an increase in depressive symptoms in girls is specific or only due to an attention effect. The situation is even more complex because the adolescents and their teachers knew about the assignment of the students to the intervention or non-intervention control group due to the fact that common school lessons took place in the control group. This may have influenced the answers of the students, which is especially problematic considering the exclusive usage of student-reports. However, if this were true, the effects should have been similar for both sexes, but the findings show different effects for girls and boys.

As already mentioned, the exclusive usage of student-reports is another limitation. Demand characteristics may have led adolescents in the intervention condition to infer desired answers from the content of the intervention. However, previous studies have demonstrated adolescents to be a reliable source of information for internalization disorders such as 
depression (Inderbitzen, 1994) and self-reports of adolescent behavior to be valid measurements (Hops, Alpert, \& Davis, 1997). In addition, depression measured by selfreport has a high predictive validity (Gotlib, Lewinsohn, \& Seeley, 1995).

However, meta-analytic studies demonstrated that female participants are more easily influenced than male participants (Cooper, 1979; Eagly \& Carli, 1981). Thus, it is possible that the positive effects of the prevention program on girls in the presented study are caused by demand characteristics. Nevertheless, only about $1 \%$ of the variance in the persuasibility and conformity can be explained by its sex (Eagly \& Carli, 1981), and even the $1 \%$ of explained variance in persuasibility and conformity is probably an overestimation. For example, Eagly and Chrvala (1986) found the sex difference in persuasibility and conformity only in adult participants but not in participants younger than 18 years. As all cited prevention studies and the current study worked with adolescents, it seems likely that demand characteristics have similar effects on adolescent boys and girls.

A further limitation is the already discussed lack of assessments of the knowledge at baseline and the relatively low internal consistency and test-retest reliability of the knowledge-test. Especially low internal consistency and test-retest reliability can be at least partially responsible for the finding that controlling for knowledge reduces the sex difference only trivial.

The fact that boys were predominantly in larger groups and girls in smaller groups is especially problematic as it can not be excluded that group size might be a confounding factor in the presented study. Unfortunately, it was not be possible to estimate the interaction effect of group size and intervention as the intervention effect cannot be modeled properly without including sex for both substantive and empirical reasons. Substantively, the intervention was provided in single-sex groups. Therefore, sex should be included in the model. Empirically, the change in depression for boys and girls is different - with boys having a linear change and girls having a quadratic change. If it is not possible to account for sex in the model, the shape 
of the trajectory over time can not be modeled appropriately for all students. However, while it was not possible to include sex, group size, and intervention in one model due to multicollinearity, subsets of those variables were examined. These analyses revealed that groups did not differ in their change in depression after accounting for sex and that smaller group size did not predict 12-month follow-up knowledge of intervention content above and beyond sex and intervention. Therefore, it seems unlikely that the sex differences in the intervention effects on depressive symptoms are caused by the differences in group size between both sexes.

A final limitation is that the mastery of trained skills and the application of those skills in the everyday lives of the adolescents were not measured. Instead, knowledge of the program content was measured as a proxy. Thus, future research could benefit from measuring changes in social information processing (Dodge, 1993) and social behavior. Despite these limitations, the low drop-out rate of approximately $10 \%$ and no recruiting difficulties, which support a high generalization of the results, are strengths of this study. In summary, the cognitive-behavioral, school-based universal prevention program LARS\&LISA had positive effects on the depressive symptoms of girls for longer time than expected. The integration of a motivation section based on Kanfer and Gaelick-Buys' (1991) self-management approach into LARS\&LISA and also the school-cohort system in German schools are a possible explanations that should be studied further. In addition, girls in the intervention group had significantly greater knowledge of both the cognitive and social content of the program, a proxy for the mastery application of skills trained in this cognitivebehavioral program, than both the girls in the control group and the boys, and this knowledge provided a potential explanation of changes in depression as evidence by a non-significant sex difference in the rate of acceleration and a marginally significant intervention-by-sex interaction and reduced effect size. Considering the lack of definitive evidence, this result needs to be studied further. If replicated, this result would demonstrate the importance of 
Course of effects in prevention of depression 37

both cognitive and social components in the prevention of depression in adolescents.

Moreover, other explanations of variability in changes in depression should be explored in future research. 
Course of effects in prevention of depression 38

\section{Acknowledgments}

We would like to thank the adolescents, parents, and teachers involved in this project and express our gratitude to the local education agency of Tübingen, Germany, for making this project possible. The described publication was made possible by Grant PO 766/1-1 to the first and last author from the German Research Foundation. 


\section{References}

Abramson, L.Y., Alloy, L.B., \& Metalsky, G.I. (1989). Hopelessness depression: A theorybased subtype of depression. Psychological Bulletin, 96, 358-372.

Achenbach, T. M. (1991). Manual for the Child Behavior Checklist $14-18$ and 1991 profile. Burlington, VT: University of Vermont Department of Psychiatry.

Angold, A., Erkanli, A., Silberg, J., Eaves, L., \& Costello, E. J. (2002). Depression scale scores in 8-17-year-olds: Effects of age and gender. Journal of Child Psychology and Psychiatry, 43, 1052-1063.

Atkins, M. \& Rohrbeck, C. A. (1993). Gender effects in self-management training: individual versus cooperative interventions. Psychology in the Schools, 30, 362-368.

Barnette, J. J. (2005). ScoreRel CI: An EXCEL program for computing confidence intervals for commonly used score reliability coefficients. Educational and Psychological Measurement, 65, $980-983$.

Barrett, P. M., Farrell, L. J., Ollendick, T. H., \& Dadds, M. (2006). Long-term outcomes of an Australian universal prevention trial of anxiety and depression symptoms in children and youth: an evaluation of the Friends program. Journal of Clinical Child and Adolescent Psychology, 35, 403-411.

Beck, A. T., Rush, A. J., Shaw, B. F., \& Emery, G. (1979). Cognitive therapy of depression. New York: The Guilford Press.

Bell, D. J., Luebbe, A. M., Swenson, L. P., \& Allwood, M. A. (2009). The Children's Evaluation of Everyday Social Encounters Questionnaire: Comprehensive assessment of children's social information processing and its relation to internalizing problems. Journal of Clinical Child \& Adolescent Psychology, 38, $705-720$.

Birmaher B., Ryan N. D., Williamson, D. E., Brent, D. A., Kaufman, J., Dahl, R.E., ... Nelson, B. (1996). Childhood and adolescent depression: A review of the past 10 
years. Part I. Journal of the American Academy of Child and Adolescent Psychiatry, $35,1427-1439$.

Brunwasser, S. M., Gillham, J. E. \& Kim, E. S. (2009). A meta-analytic review of the Penn Resiliency Program's effects on depressive symptoms. Journal of Consulting and Clinical Psychology, 77, 1042 - 1054.

Chaplin, T. M., Gillham, J. E., Reivich, K., Elkon, A. G. L., Samuels, B., Freres, D. R., ... Seligman, M. E. P. (2006). Depression prevention for early adolescent girls: A pilot study of all girls versus co-ed groups. Journal of Early Adolescence, 26, 110-126.

Clarke, G. N., Hawkins, W., Murphy, M., \& Sheeber, L. (1993). School-based primary prevention of depressive symptomatology in adolescents. Findings from two studies. Journal of Adolescent Research, 8, 183-204.

Cobham, V. E., Dadds, M. R., \& Spence, S. H. (1998). The role of parental anxiety in the treatment of childhood anxiety. Journal of Consulting \& Clinical Psychology, 66, 893-905.

Cohen, J. (1992). A power primer. Psychological Bulletin, 112, 155-159.

Cooper, H. M. (1979). Statistically combining independent studies: A meta-analysis of sex differences in conformity research. Journal of Personality and Social psychology, 37, 131 146.

Costello, E. J., Erkanli, A., \& Angold, A. (2006). Is there an epidemic of child or adolescent depression? Journal of Child Psychology and Psychiatry, 47, 1263 - 1271.

Costello, E. J., Foley, D. L., \& Angold, A. (2006). 10-year research update review: The epidemiology of child and adolescent psychiatric disorders: II. Developmental epidemiology. Journal of the American Academy of Child and Adolescent Psychiatry, 45, 8 -25 . 
Cuijpers, P., van Straten, A., Andersson, G., \& van Oppen, P. (2008). Psychotherapy of depression in adults: A meta-analysis of comparative outcome studies. Journal of Consulting and Clinical Psychology, 76, 909 - 922.

Dodge, K. A. (1993). Social-cognitive mechanisms in the development of conduct disorder and depression. Annual Review of Psychology, 44, 559-584.

Döpfner, M., Götz-Dorten, A., \& Lehmkuhl, G. (2008). Diagnostik-System für Psychische Störungen im Kindes- und Jugendalter nach ICD-10 und DSM-IV, DISYPS-II [Diagnostic system for mental disorders in children and adolescents based upon the ICD-10 and DSM-IV]. Bern, Switzerland: Huber.

Duckworth, A., \& Seligman, M. (2006). Self-discipline gives girls the edge: Gender in selfdiscipline, grades, and achievement test scores. Journal of Educational Psychology, 98, $198-208$.

Eagly, A. H. \& Carli, L. L. (1981). Sex of researchers and sex-typed communications as determinants of sex differences in influencability: A meta-analysis of social influence studies. Psychological Bulletin, 90, 1 - 20.

Eagly, A. H. \& Chrvala, C. (1986). Sex differences in conformity: Status and gender role interpretations. Psychology of Women Quarterly, 10, 203 - 220

Garber, J. \& Downs, L. E. (2011). Prevention of depression in youth: sex differences in effects. In T. J. Strauman, P. R. Costanzo, \& J. Garber (Eds.). Preventing depression among adolescent girls: From basic research to effective intervention (pp. 193-234). New York, NY: Guilford Press.

Garber, J., Keiley, M. K., \& Martin, N. C. (2002). Developmental trajectories of adolescents' depressive symptoms: Predictors of change. Journal of Consulting and Clinical Psychology, 70, 79 - 95. 
Ge, X., Conger, R. D., \& Elder, G. H. (2001). Pubertal transition, stressful life events, and the emergence of gender differences in adolescent depressive symptoms. Developmental Psychology, 37, 404-417.

Georgiades, K., Lewinsohn, P. M., Monroe, S. M., \& Seeley, J. R. (2006). Major depressive disorder in adolescence: The role of subthreshold symptoms. Journal of the American Academy of Child and Adolescent Psychiatry, 45, 936-944.

Gifford-Smith, M., Dodge, K. A., Dishion, T. J., \& McCord, J. (2005). Peer influence in children and adolescents: Crossing the bridge from developmental to intervention science. Journal of Abnormal Child Psychology, 33, 255-265.

Gillham, J. E., Hamilton, J., Freres, D. R., Patton, K., \& Gallop, R. (2006). Preventing depression among early adolescents in the primary care setting: A randomized controlled study of the Penn Resiliency Program. Journal of Abnormal Child Psychology, 34, 203-219.

Gillham, J. E., Reivich, K. J., Jaycox, L. H. \& Seligman, M. E. P. (1995). Prevention of depressive symptoms in schoolchildren: Two-year follow-up. Psychological Science, $6,343-351$.

Goldstein, H. (1995). Multilevel statistical models (2nd ed.). London: Arnold.

Goldstein, B. I. (2006). Why do women get depressed and men get drunk? An examination of attributional style and coping style in response to negative life events among Canadian young adults. Sex Roles, 54, 27 - 37.

Gómez, Y., Jimenez J.C. \& Restrepo, V. (2004). Evaluación del programa LISA PD para la prevención de la depresión en adolescentes: Un aprueba piloto. IV Congreso Iberoamericano de Psicología clínica y de la salud.

Gotlib, I. H., Lewinsohn, P. M., \& Seeley, J. R. (1995). Symptoms versus a diagnosis of depression: Differences in psychosocial functioning. Journal of Consulting and Clinical Psychology, 63, 90-100. 
Groen, G., Pössel, P., Al-Wiswasi, S., \& Petermann, F. (2003). Universelle, schulbasierte Praevention der Depression im Jugendalter: Ergebnisse einer Follow-up-Erhebung nach elf Monaten. [Universal schoolbased prevention of depression among adolescents. Results of a 11-month follow-up.] Kindheit und Entwicklung, 12, 164 174.

Groen, G., Pössel, P., \& Petermann, F. (2003). Depression im Kindes- und Jugendalter. [Depression in childhood and adolescence] In F. Petermann, K. Niebank \& H. Scheithauer (Eds.), Lehrbuch der Entwicklungswissenschaft: Entwicklungspsychologie, Genetik, Neuropsychologie [Textbook of Development Science: Developmental psychology, genetic, neuropsychology] (pp. 437 - 481). Berlin, Germany: Springer.

Hankin, B. L. \& Abramson, L. Y. (2001). Development of gender differences in depression: An elaborated cognitive vulnerability-transactional stress theory. Psychological Bulletin, 127, 773-796.

Hankin, B. L., Abramson, L. Y., Moffitt, T. E., McGee, R., Silva, P. A., \& Angell, K. E. (1998). Development of depression from preadolescence to young adulthood: Emerging gender differences in a 10-year longitudinal study. Journal of Abnormal Psychology, 107, $128-140$.

Honigsfeld, A. \& Dunn, R. (2003). High school male and female learning-style similarities and differences in diverse nations. The Journal of Educational Research, 96, 159-206.

Hopkins, K. D. (1982). The unit of analysis: Group means versus individual observations. American Educational Research Journal, 19, 5-18.

Hops, H., Alpert, A., \& Davis, B. (1997). The development of same- and opposite-sex social relations among adolescents: An analogue study. Social Development, 6, 165-183. 
Horowitz, J. L. \& Garber, J. (2006). The prevention of depressive symptoms in children and adolescents: A meta-analytic review. Journal of Consulting and Clinical Psychology, $74,401-415$.

Horowitz, J.L., Garber, J., Ciesla, J.A., Young, J., \& Mufson, L. (2007). Preventing depression in adolescents: A comparison of two universal prevention programs. Journal of Consulting and Clinical Psychology, 75, 693-706.

Inderbitzen, H. M. (1994), Adolescent peer social competence. A critical review of assessment methodologies and instruments. In T. H. Ollendick \& R. J. Prinz (Eds.), Advances in clinical child psychology, 16. New York, NY: Plenum Press.

Jaycox, L. H., Reivich, K. J., Gillham, J., \& Seligman, M. E. P. (1994). Prevention of depressive symptoms in school children. Behaviour Research and Therapy, 32, 801 816.

Kanfer, F. H. \& Gaelick-Buys, L. (1991). Self-management methods. In F. H. Kanfer \& A. P. Goldstein (Eds.), Helping people change. New York, NY: Pergamon.

Kenney-Benson, G. A., Pomerantz, E. M., Ryan, A. M., \& Patrick, H. (2006). Sex differences in math performance: The role of children's approach to schoolwork. Developmental Psychology, 42, $11-26$.

Klasen, H., Woerner, W., Wolke, D., Meyer, R., Overmeyer, S., Kaschnitz, W., ... Goodman, R. (2000). Comparing the German versions of the Strengths and Difficulties Questionnaire (SDQ-Deu) and the Child Behavior Checklist. European Child and Adolescent Psychiatry, 9, 271-276.

McCoach, D. B., \& Adelson, J. L. (2010). Dealing with dependence (Part I): Understanding the effects of clustered data. Gifted Child Quarterly, 54, 152-155. DOI: $10.1177 / 0016986210363076$

Meece, J. L., \& Holt, K. (1993). A pattern analysis of students' achievement goals. Journal of Educational Psychology, 85, 582 - 590. 
Merry, S., McDowell, H., Wild, C. J., Bir, J., \& Cunliffe, R. (2004). A randomized placebocontrolled trial of a school-based depression prevention program. Journal of the American Academy of Child and Adolescent Psychiatry, 43, 538-547.

Merry, S., McDowell, H., Hetrick, S., Bir, J., \& Muller, N. (2006). Psychological and/or educational interventions for the prevention of depression in children and adolescents (Review). The Cochrane Library, 4, np.

Nolen-Hoeksema, S. (2006). The Etiology of Gender Differences in Depression. In C. M. Mazure, \& G. P. Keita (Eds.), Understanding depression in women: Applying empirical research to practice and policy (pp. 9-43). Washington, DC: American Psychological Association.

Nolen-Hoecksema, S. \& Girgus, J. S. (1994). The emergence of gender differences in depression during adolescence. Psychological Bulletin, 115, 424 - 443.

Offord, D. R. (2000). Selection of levels of prevention. Addictive Behavior, 25, $833-842$.

Pennebaker, J.W. \& Bell, S.K. (1986). Confronting a traumatic event: Toward an understanding of inhibition and disease. Journal of Abnormal Psychology, 95, 274-281.

Petersen, A. C., Leffert, N., Graham, B., Alwin, J., \& Ding, S. (1997). Promoting mental health during the transition into adolescence. In J. Schulenberg, J. L. Maggs, \& A. K. Hurrelmann (Eds.), Health risks and developmental transitions during adolescence (pp. 471-497). New York: Cambridge University Press.

Pössel, P., Baldus, C., Horn, A. B., Groen, G., \& Hautzinger, M., (2005). Influence of general self-efficacy on the effects of a school-based universal primary prevention program of depressed symptoms in adolescents: a randomized and controlled follow-up study. Journal of Child Psychology and Psychiatry, 46, 982-994.

Pössel, P., Horn, A. B., \& Hautzinger, M. (2003). Erste Ergebnisse eines Programms zur schulbasierte Prävention von depressiven Symptomen bei Jugendlichen [First results 
of a school-based prevention program of depressive symptoms in adolescents]. Zeitschrift für Gesundheitspsychologie, 11, 10-20.

Pössel, P., Horn, A. B., \& Hautzinger, M. (2006). Vergleich zweier schulbasierter Präventionsprogramme von depressiven Symptomen bei Jugendlichen. [Comparison of two prevention programs of depressive symptoms in adolescents.] Zeitschrift für Klinische Psychologie und Psychotherapie, 35, 109 - 116.

Pössel, P., Horn, A. B., Hautzinger, M., \& Groen, G. (2004), School-based universal primary prevention of depressive symptoms in adolescents: Results of a 6-month follow-up. Journal of the American Academy of Child and Adolescent Psychiatry, 43, 1003-1010.

Pössel, P., Horn, A. B., Seemann, S., \& Hautzinger, M. (2004). Trainingsprogramm zur Prävention von Depressionen bei Jugendlichen. LARS\&LISA: Lust An Realistischer Sicht \& Leichtigkeit Im Sozialen Alltag [A training to prevent depression among adolescents. LARS\&LISA: The joy of taking a realistic view \& Easy-goingness in everyday social life]. Hogrefe, Germany: Göttingen.

Pössel, P., Schneider, S., \& Seemann, S. (2006). Effekte und Kosten universaler Praevention von Internalisierungsstoerungen bei Kindern und Jugendlichen [Effects and costs of universal prevention of internalization disorders in children and adolescents]. Verhaltenstherapie, 16, 201-210.

Pössel, P., Seemann, S., Ahrens, S., \& Hautzinger, M. (2006). Testing the causal mediation component of Dodge's social information processing model of social competence and depression. Journal of Youth and Adolescence, 35, 849-859.

Pössel, P., Seemann, S., \& Hautzinger, M. (2008). Impact of comorbidity in prevention of adolescent depressive symptoms. Journal of Counseling Psychology, 55, 106-117.

Pössel, P. \& Thomas, S. D. (2010). Cognitive Triad as mediator in the Hopelessness model? A three-wave longitudinal study. Manuscript submitted for publication. 
Quiggle, N.L., Garber, J., Panak, W.F., \& Dodge, K.A. (1992). Social information processing in aggressive and depressed children. Child Development, 63, 1305-1320.

Raudenbush, S., \& Bryk, A. (2002). Hierarchical linear models (2nd ed.). Newbury Park, CA: Sage.

Raudenbush, S. Bryk, A. Cheong, Y. F., \& Congdon, R., \& du Toit, M. (2004). HLM6: Hierarchical linear and non-linear modeling. Lincolnwood, IL: Scientific Software International.

Raudenbush, S.W. \& Liu, X. (2001). Effects of study duration, frequency of observation, and sample size on power in studies of group differences in polynomial change. Psychological Methods, 6, 387-401.

Rutter, M., Caspi, A., \& Moffitt, T. E. (2003). Using sex differences in psychopathology to study causal mechanisms: Unifying issues and research. Journal of Child Psychiatry and Psychology, 44, $1092-1115$.

Shatté, A. J. (1996). Prevention of depressive symptoms in adolescents: Issues of dissemination and mechanisms of change. Unpublished doctoral dissertation, University of Pennsylvania.

Shochet, I. M., Dadds, M. R., Holland, D., Whitefield, K., Harnett, P. H., \& Osgarby, S. M. (2001). The efficacy of a universal school-based program to prevent adolescent depression. Journal of Clinical Child Psychology, 30, 303-315.

Spence, S. H., Sheffield, J. K., \& Donovan, C. L. (2003). Preventing adolescent depression: An evaluation of the Problem Solving for Life Program. Journal of Consulting and Clinical Psychology, 71, 3-13.

Spence, S. H., Sheffield, J. K., \& Donovan, C. L. (2005). Long-term outcome of a schoolbased, universal approach to prevention of depression in adolescents. Journal of Consulting and Clinical Psychology, 73, 160-167. 
Stice, E., Shaw, H., Bohon, C., Marti, C. N., \& Rohde, P. (2009). A meta-analytic review of depression prevention programs for children and adolescents: factors that predict magnitude of intervention effects. Journal of Consulting and Clinical Psychology, 77, $486-503$.

Stone, L. B., Gibb, B. E., \& Coles, M. E. (2010). Does the hopelessness theory account for sex differences in depressive symptoms among young adults? Cognitive Therapy and Research, 34, $177-187$.

Sukhnandan, L., Lee, B., \& Kelleher, S. (2000). An investigation into gender differences and achievement: Phase 2. School and classroom strategies. Slough, England: National Foundation for Educational Research.

Wahl, M.S., Patak, M.A., Pössel, P. \& Hautzinger, M. (in press). A School-based Universal Programme to Prevent Depression and to Build Up Life Skills. Journal of Public Health.

Warrington, M. \& Younger, M. (2003). 'We decided to give it a twirl': Single-sex teaching in English comprehensive schools. Gender and Education, 15, 339-350.

Weissman, M. M., Wolk, S., Goldstein, R. B., Moreau, D., Adams, P., Greenwald, S., ... Wickramaratne, P. (1999). Depressed adolescents grow up. Journal of the American Medical Association, 281, 1707-1713.

Woerner, W., Becker, A., Friedrich, C., Klasen, H., Goodman, R., \& Rothenberger, A. (2002). Normierung und Evaluation der deutschen Elternversion des Strengths and Difficulties Questionnaire (SDQ): Ergebnisse einer repräsentativen Felderhebung [Normation and evaluation of the German parent version of the Strengths and Difficulties Questionnaire (SDQ): Results of representative field study]. Zeitschrift für Kinder- und Jugendpsychiatrie und Psychotherapie, 30, 105-112. 
Table 1

Descriptive Statistics of Depressive Symptoms, Conduct Problems, and Knowledge, Separated According to Sex and Measurement Times

\begin{tabular}{lll}
\hline Intervention group & Control group
\end{tabular}

Boys $\quad$ Girls $\quad$ Boys $\quad$ Girls

Mean SD Mean SD Mean SD Mean SD

Age

$\begin{array}{llllllll}13.74 & 0.66 & 13.72 & 0.59 & 13.67 & 0.58 & 13.59 & 0.58\end{array}$

$(n=91)$

$(n=72)$

$(n=70)$

$(n=68)$

SBB-DES at baseline

$\begin{array}{llllllll}0.51 & 0.42 & 0.70 & 0.50 & 0.52 & 0.46 & 0.56 & 0.41\end{array}$

$(n=91)$

$(n=72)$

$(n=70)$

$(n=68)$

SBB-DES at post-intervention

0.57

0.49

$0.75 \quad 0.62$

$0.57 \quad 0.47$

$(n=85)$

$(n=68)$

$(n=64)$

$(n=66)$

SBB-DES at 6-mfu

$0.67 \quad 0.66$

0.55

0.48

$0.67 \quad 0.66$

$0.58 \quad 0.45$

$(n=83)$

$(n=70)$

$(n=66)$

$(n=66)$

SBB-DES at 12-mfu

$\begin{array}{llllllll}0.80 & 0.67 & 0.53 & 0.51 & 0.75 & 0.65 & 0.71 & 0.55\end{array}$

$(n=77)$

$(n=61)$

$(n=63)$

$(n=58)$

SDQ at baseline

$2.29 \quad 1.40$

2.22

1.47

2.71

1.99

$2.47 \quad 1.46$

$(n=91)$

$(n=72)$

$(n=70)$

$(n=68)$

SDQ at post-intervention

$$
3.16
$$

1.92

2.22

1.44

2.77

1.72

2.50

1.45

$(n=85)$

$(n=68)$

$(n=64)$

$(n=66)$

SDQ at 6-mfu

2.90

1.7

2.24

1.63

2.83

1.68

2.23

$(n=84)$

$(n=70)$

$(n=66)$

$(n=66)$

SDQ at 12-mfu

$3.65 \quad 2.10$

2.30

1.46

$3.14 \quad 1.97$

$2.17 \quad 1.50$

$(n=77)$

$(n=61)$

$(n=63)$

$(n=58)$ 
Course of effects in prevention of depression 50

$\begin{array}{lllllllll}\text { Cognitive knowledge at post- } & 3.63 & 0.69 & 3.71 & 0.64 & 3.47 & 0.59 & 3.51 & 0.65\end{array}$ intervention

$$
(n=85) \quad(n=68) \quad(n=64) \quad(n=65)
$$

Social knowledge at post-

$\begin{array}{llll}3.72 & 0.69 & 4.00 & 0.58\end{array}$

$3.11 \quad 0.69$

$3.27 \quad 0.70$

intervention

$$
(n=86) \quad(n=68) \quad(n=64) \quad(n=65)
$$

Total knowledge at postintervention

$$
(n=85) \quad(n=68) \quad(n=64) \quad(n=65)
$$

Cognitive knowledge at 6-mfu

$$
3.89 \quad 0.64
$$

4.22

0.48

$3.71 \quad 0.59$

$3.79 \quad 0.49$

$(n=83)$

$(n=68)$

$(n=65)$

$(n=65)$

Social knowledge at 6-mfu

$3.89 \quad 0.73$

4.31

0.51

$3.56 \quad 0.66$

$3.67 \quad 0.54$

$(n=83)$

$(n=68)$

$(n=65)$

$(n=65)$

Total knowledge at 6-mfu

$7.78 \quad 1.21$

$8.53 \quad 0.85$

7.27

1.03

$7.46 \quad 0.83$

$(n=83)$

$(n=68)$

$(n=65)$

$(n=65)$

Cognitive knowledge at 12-

$$
3.59 \quad 0.74
$$

3.98

0.61

$\begin{array}{ll}3.52 & 0.67\end{array}$

$3.72 \quad 0.62$

mfu

$$
(n=77) \quad(n=61) \quad(n=62) \quad(n=58)
$$

Social knowledge at 12-mfu

$3.83 \quad 0.74$

4.26

0.72

3.6

0.79

$3.85 \quad 0.62$

$(n=77)$

$(n=61)$

$(n=62)$

$(n=58)$

Total knowledge at 12-mfu

$7.42 \quad 1.29$

$8.24 \quad 1.08$

7.17

1.18

$\begin{array}{ll}7.57 & 0.89\end{array}$

$(n=77)$

$(n=61)$

$(n=62)$

$(n=58)$

Note. SBB-DES = Self-Report Questionnaire-Depression; SDQ = Strengths and Difficulties

Questionnaire, Conduct problems scale; $\mathrm{mfu}=$ month follow-up; $+=p<.10 ; *=p<.05 ; * *$ $=p<.01$. 
Table 2

Summary of FIML Fixed Effects Estimates for Final Three-Level Model of Depression $(n=$ 297 Students)

Parameter Parameter estimate SE

Model for baseline depression $\left(\pi_{0}\right)$

Model for intercept baseline depression $\left(\beta_{00}\right)$

$$
\text { Intercept }\left(\gamma_{000}\right)
$$

$0.553 * * *$

0.036

Model for sex $\left(\beta_{0}\right)$

$$
\text { Intercept }\left(\gamma_{010}\right)
$$

0.072

0.053

Model for linear growth slope $\left(\pi_{1}\right)$

Model for intercept linear growth $\left(\beta_{10}\right)$

$\begin{array}{lcc}\text { Intercept }(\text { TIME })\left(\gamma_{100}\right) & 0.030 * & 0.013 \\ \text { Intervention }\left(\gamma_{101}\right) & 0.003 & 0.006\end{array}$

Model for sex $\left(\beta_{11}\right)$

$$
\begin{array}{lll}
\text { Intercept }\left(\gamma_{110}\right) & -0.048^{* *} & 0.017
\end{array}
$$

Model for rate of acceleration $\left(\pi_{2}\right)$

Model for intercept rate of acceleration $\left(\beta_{20}\right)$

$$
\begin{array}{lll}
\text { Intercept }\left(\mathrm{TIME}^{2}\right)\left(\gamma_{200}\right) & -0.001 & 0.001
\end{array}
$$

Model for sex $\left(\beta_{21}\right)$

$\begin{array}{lll}\text { Intercept }\left(\gamma_{210}\right) & 0.003^{*} & 0.001 \\ \text { Intervention }\left(\gamma_{211}\right) & -0.001^{*} & 0.001\end{array}$

Note. FIML = full maximum likelihood estimation. Sex is dummy coded 0 for boy and 1 for girl. Time is measured in months. Intervention is an indicator of group and is dummy coded 0 for control group and 1 for intervention group. * $p<.05 ; * * p<.01 ; * * * p<.001$. 
Table 3

Summary of FIML Fixed for Three-Level Models Examining Possible Explanations for Sex and Intervention-by-Sex Effects on Rate of Acceleration of Depression ( $n=297$ Students)

\begin{tabular}{|c|c|c|c|c|}
\hline \multirow{2}{*}{ Parameter } & \multicolumn{4}{|c|}{ Parameter estimate (SE) } \\
\hline & Conduct & Cognitive knowledge & Social knowledge & Total knowledge \\
\hline \multicolumn{5}{|l|}{ Model for baseline depression $\left(\pi_{0}\right)$} \\
\hline \multicolumn{5}{|c|}{ Model for intercept baseline depression $\left(\beta_{00}\right)$} \\
\hline Intercept $\left(\gamma_{000}\right)$ & $0.55(0.03)^{* * *}$ & $0.55(0.04)^{* * *}$ & $0.55(0.04)^{* * *}$ & $0.55(0.04) * * *$ \\
\hline \multicolumn{5}{|l|}{ Model for sex $\left(\beta_{0}\right)$} \\
\hline Intercept $\left(\gamma_{010}\right)$ & $0.07(0.05)$ & $0.07(0.05)$ & $0.07(0.05)$ & $0.07(0.05)$ \\
\hline \multicolumn{5}{|l|}{ Model for linear growth slope $\left(\pi_{1}\right)$} \\
\hline \multicolumn{5}{|c|}{ Model for intercept linear growth $\left(\beta_{10}\right)$} \\
\hline Intercept (TIME) $\left(\gamma_{100}\right)$ & $0.03(0.01)^{*}$ & $0.03(0.01)^{*}$ & $0.03(0.01)^{*}$ & $0.03(0.01)^{*}$ \\
\hline \multicolumn{5}{|l|}{ Model for sex $\left(\beta_{11}\right)$} \\
\hline Intercept $\left(\gamma_{110}\right)$ & $-0.05(0.02)^{* *}$ & $-0.05(0.02)^{* *}$ & $-0.05(0.02)^{* *}$ & $-0.05(0.02)^{* *}$ \\
\hline \multicolumn{5}{|l|}{ Model for rate of acceleration $\left(\pi_{2}\right)$} \\
\hline \multicolumn{5}{|c|}{ Model for intercept rate of acceleration $\left(\beta_{20}\right)$} \\
\hline Intercept $\left(\mathrm{TIME}^{2}\right)\left(\gamma_{200}\right)$ & $-0.001(0.0009)$ & $-0.001(0.001)$ & $-0.001(0.001)$ & $-0.001(0.001)$ \\
\hline \multicolumn{5}{|l|}{ Model for sex $\left(\beta_{21}\right)$} \\
\hline Intercept $\left(\gamma_{210}\right)$ & $0.003(.001)^{*}$ & $0.003(0.001)^{* *}$ & $0.0003(0.001)^{*}$ & $0.003(0.001)^{* *}$ \\
\hline Intervention $\left(\gamma_{211}\right)$ & $-0.001(0.0004)^{*}$ & $-0.0009(0.0004)$ & $-0.0009(0.0005)^{*}$ & $-0.0008(0.0005)$ \\
\hline \multicolumn{5}{|c|}{ Model for explanatory variable $\left(\beta_{22}\right)$} \\
\hline Intercept $\left(\gamma_{220}\right)$ & $0.00006(0.0001)$ & $-0.001(0.0003)^{* * *}$ & $-0.0008(0.0003)^{* *}$ & $-0.0008(0.0002)^{* * *}$ \\
\hline \multicolumn{5}{|c|}{ Model for sex-by-explanatory $\left(\beta_{23}\right)$} \\
\hline Intercept $\left(\gamma_{230}\right)$ & $0.00005(0.0002)$ & $0.001(0.0004)^{*}$ & $0.0007(0.0004)$ & $0.0005(0.0003)^{*}$ \\
\hline
\end{tabular}




\section{Registered students ( $n=347$ )}
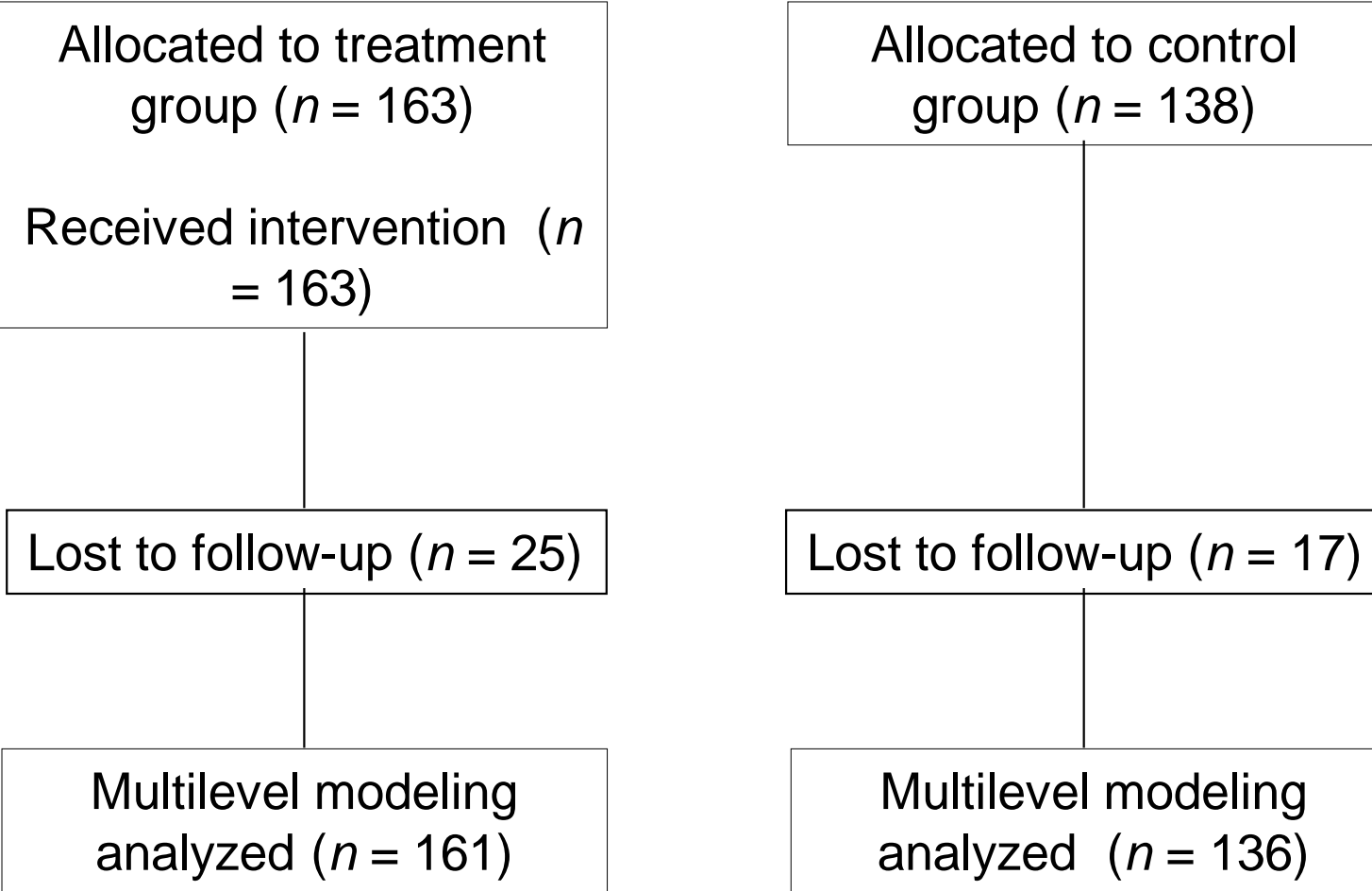

Randomization

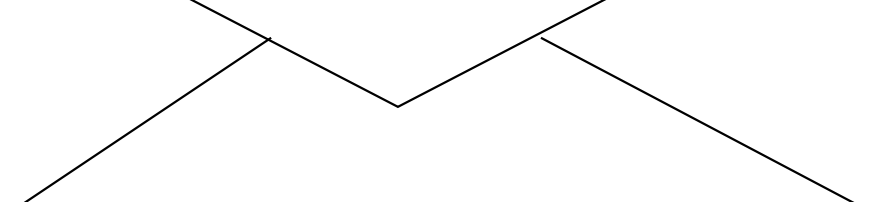

Allocated to control group $(n=138)$
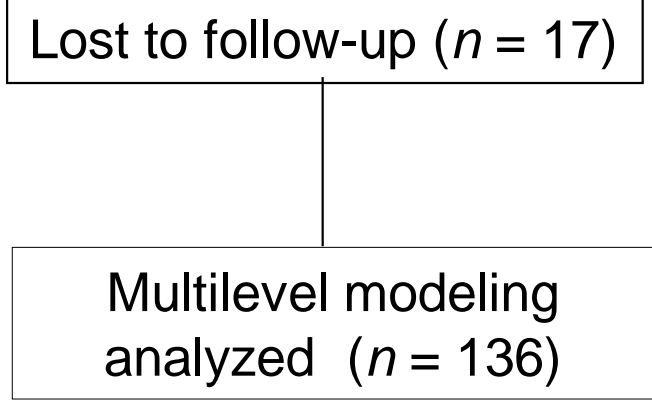

Figure 1. Flow chart describing sample size and dropout of students within the study. 


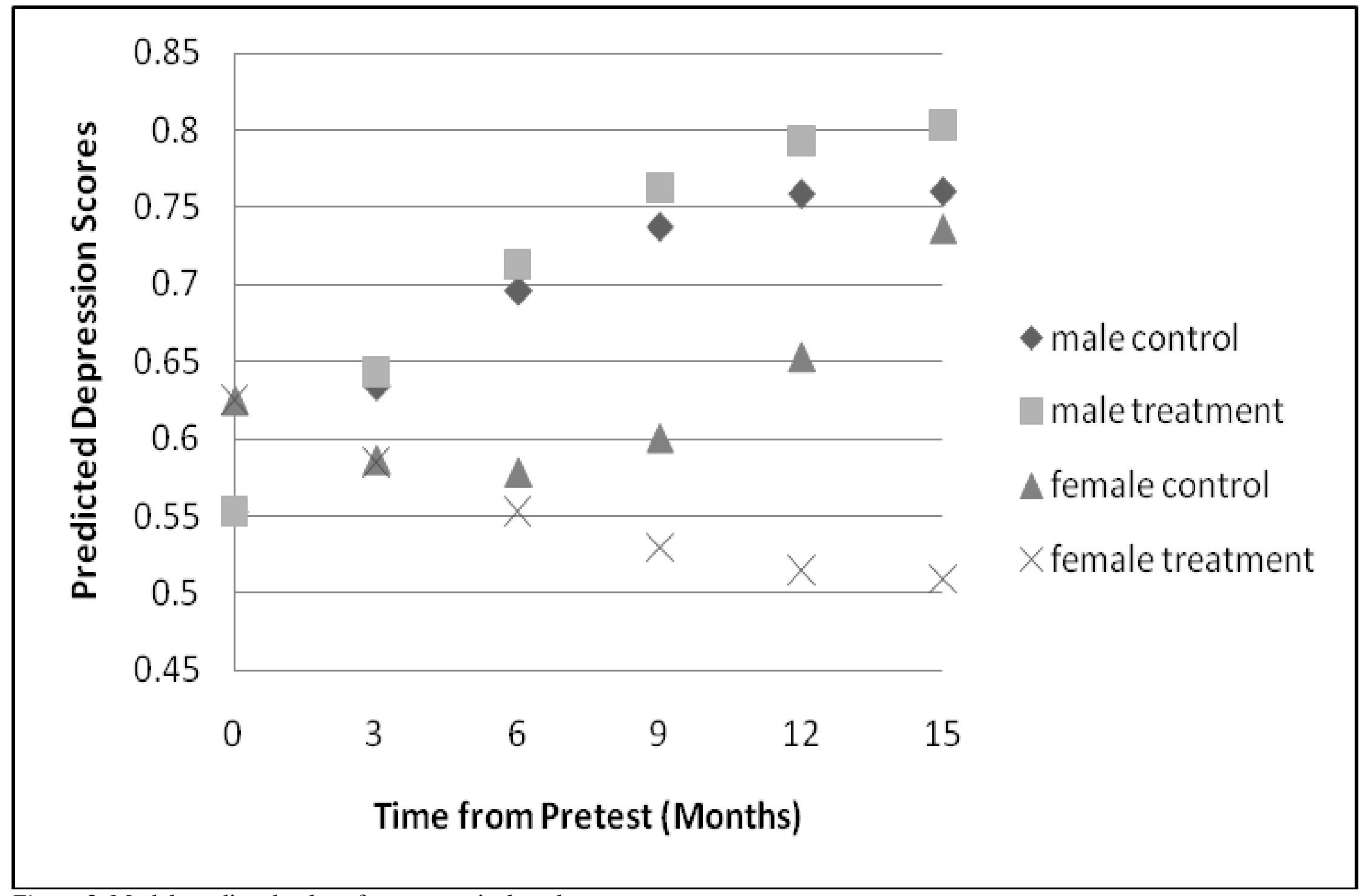

Figure 2. Model-predicted values for prototypical students. 